\title{
TERRITORIALIZAÇÃO DO COTIDIANO A PARTIR DE INTERVENÇÕES GOVERNAMENTAIS: $O$ CASO DAS ACADEMIAS DA TERCEIRA IDADE (ATIS)
}

TERRITORIALIZATION OF EVERYDAY LIFE BASED ON GOVERNMENT INTERVENTIONS: THE CASE OF THIRD AGE GYMS (ATIS)

\section{TERRITORIALIZACIÓN DEL COTIDIANO A PARTIR DE INTERVENCIONES GUBERNAMENTALES: EL CASO DE LAS ACADEMIAS DE LA TERCERA EDAD (ATIS)}

\author{
FERNANDA GUARNIERI \\ Doutoranda \\ Universidade Estadual de Maringá - Brasil \\ fernandamguarnieri@gmail.com
}

PRISCILLA BORGONHONI CHAGAS

Doutora

Universidade Estadual de Maringá - Brasil

pbchagas@uem.br

FRANCISCO GIOVANNI DAVID VIEIRA
Doutor
Universidade Estadual de Maringá - Brasil
fgdvieira@uem.br

Submetido em: 24/03/2017

Aprovado em: 22/06/2018

Doi: alcance.v25n1(Jan/Abr).p61-78

\begin{abstract}
RESUMO
Ao articular de forma teórica o avanço sobre espaço e territórios no campo de Estudos Organizacionais com a abordagem sobre o cotidiano, o presente artigo busca compreender como ocorre a territorialização do cotidiano dos moradores de um determinado bairro a partir da produção do espaço urbano por meio de intervenções governamentais com a implantação de Academias da Terceira Idade (ATIs), que surgiram como uma estratégia para promoção da saúde e da qualidade de vida, influenciada por um contexto marcado pela transição demográfica. $\mathrm{O}$ estudo tem uma perspectiva qualitativa e caráter descritivo. Os procedimentos metodológicos adotados envolveram a pesquisa documental e a realização de trabalho de campo com entrevistas com idosos que frequentam semanalmente uma ATI em um dos bairros de Maringá, PR, município brasileiro onde foi inaugurada a primeira ATI nacional. Os dados coletados foram analisados por meio da análise de conteúdo. Verificou-se que o espaço, antes abandonado e sem uso por parte dos moradores do bairro, é agora pautado pelas territorialidades cotidianas dos usuários, que o construíram diante de movimentos de apropriação e uso. Destaca-se, também, a intervenção governamental realizada sem impactos negativos para a população, de forma que a mesma se apropriou de discursos que propagam os benefícios da ATI.
\end{abstract}

Palavras-chave: Territorialização. Cotidiano. Academia da Terceira Idade.

\section{ABSTRACT}

Through a theoretical articulation of the advances on space and territories in the field of Organizational Studies with the approach to everyday life, this article seeks to understand how territorialization occurs in the everyday lives of the residents of a particular neighborhood, based on the production of the urban space by means of government interventions, with the implementation of Third Age Gyms (ATIs). ATIs emerged as a strategy to 
promote health and quality of life, influenced by a context of demographic transition. The study uses qualitative and descriptive perspectives. The methodological procedures involved document research and fieldwork with interviews with elderly people who attend an ATI weekly in one of the neighborhoods of Maringá, the Brazilian city where the first national ATI was launched. The data collected were analyzed through content analysis. It was found that the space, previously abandoned and unused by the residents of the neighborhood, is now guided by the everyday territorialities of the users, who built it by movements of appropriation and use. It is also highlighted that the government intervention was carried without negative impacts on the population, as they have appropriated the discourses that raised awareness of the benefits of the ATI.

Keywords: Territorialization. Everyday life. Third Age Gym.

\section{RESUMEN}

Al articular de forma teórica el avance sobre espacio y territorios en el campo de Estudios Organizacionales con el abordaje sobre el cotidiano, el presente artículo busca comprender como ocurre la territorialización del cotidiano en los habitantes de un determinado barrio a partir de la producción del espacio urbano por medio de intervenciones gubernamentales con la implantación de Academias para la Tercera Edad (ATIs), que surgieron como una estrategia para promoción de la salud y de la calidad de vida, influenciada por un contexto marcado por la transición demográfica. El estudio tiene una perspectiva cualitativa y de carácter descriptivo. Los procedimientos metodológicos adoptados envuelven la investigación documental y la realización de trabajo de campo con entrevistas y ancianos que frecuentan semanalmente una ATI en uno de los barrios de Maringá, PR, municipio brasileño donde fue inaugurada la primera ATI nacional. Los datos colectados fueron analizados por medio del análisis de contenido. Se verifico que el espacio, antes abandonado y sin uso por parte de los habitantes del barrio, es ahora pautado por las territorialidades cotidianas de los usuarios, que lo construyeron delante de movimientos de apropiación y uso. Se destaca, también, la intervención gubernamental realizada sin impactos negativos para la población, de forma que la misma se apropió de discursos que propagan los beneficios de la ATI.

Palabras clave: Territorialización. Cotidiano. Academia para la Tercera Edad.

\section{INTRODUÇÃO}

Os estudos acerca de espaço e territórios estão ganhando notoriedade no campo dos Estudos Organizacionais, buscando compreender as relações espaciais e sociais, assim como a produção do espaço urbano diante de estruturas capitalistas. Para tanto, da produção do espaço urbano, há a produção da cidade, que vista como organização, é possível observar sua vida social pela lente organizacional da dinâmica urbana (SARAIVA; CARRIERI, 2012).

Adotando conceitos da geografia - espaço e território - para a análise de fenômenos organizacionais nos Estudos Organizacionais, discute-se como os agentes sociais podem alterar sua dinâmica social em função de intervenções no espaço em que vivem (SARAIVA; CARRIERI, 2012). Além disso, o espaço urbano constituise das relações sociais, condições da vida cotidiana e do modo como a sociedade se apropria desse mesmo espaço (CARLOS, 2013), não restringindo sua compreensão somente ao espaço físico (COELHO, 2012). Verifica-se, ainda, que dentre os agentes sociais, o Estado é aquele que desfruta de instrumentos mais amplos na produção do espaço (COELHO, 2012), interligando-se com os demais agentes, tanto quanto elaborando leis e normas como estratégias de políticas públicas (CORRÊA, 2004).

As estratégias de políticas públicas são compreendidas, dentre outras definições, como as atividades e as ações do governo que influenciam a vida da população (SOUZA, 2006). Para tanto, destaca-se aqui o desenvolvimento das condições de saúde e qualidade de vida a partir dessas políticas. Conforme informações do Ministério da Saúde, existem no Brasil políticas para a promoção, proteção e recuperação da saúde, priorizando ações de melhoria da qualidade de vida da população (BRASIL, 2015).

Convergente a isso, observa-se que o fenômeno de transição demográfica, que ocorre no Brasil desde 1940, influencia cada vez mais para o desenvolvimento de tais políticas (MYRRHA, 2016). Dentre suas implicações, conforme a mesma autora, destacam-se as taxas de crescimento negativas e o envelhecimento populacional. Nesse cenário, a expectativa de vida no Brasil tem avançado, de um tempo médio de 42,7 anos em 1940, para 75,7 anos em 2016. Espera-se que 30\% da população brasileira em 2050 esteja com mais de 60 anos de idade, o que acarretará maior demanda populacional quanto à saúde (MYRRHA, 2016). 
Nesse contexto, afirma-se a importância do planejamento de políticas públicas para lidar de forma correta com esse fenômeno populacional, especialmente a atenção quanto às doenças crônicas, que atinge a população de maior faixa etária (NARDI; SAPATA; LOPES, 2013). Assim sendo, em 2006 surgiu, no município de Maringá-PR, a Academia da Terceira Idade (ATI), implantada por meio do Programa Maringá Saudável e pelas Secretarias de Saúde e Esporte e Lazer. O programa da ATI é baseado em diretrizes para o investimento em ações para a promoção e a prevenção da saúde, especialmente para idosos. Para este fim, a Secretaria de Saúde realiza parcerias público-privadas (NARDI; SAPATA; LOPES, 2013) para o desenvolvimento de ações que incentivam a prática de atividade física, por meio de equipamentos públicos disponibilizados nos espaços urbanos. Atualmente existem 62 ATls no município, que foi pioneiro na instalação das mesmas em âmbito nacional (SECRETARIA MUNICIPAL DE ESPORTES E LAZER, 2017).

Analisando especificamente a cidade de Maringá, PR, observa-se que, consoante as estatísticas nacionais, a sua população também se apresenta mais envelhecida. Até 1980, a população idosa representava 4,0\% e em 2012 representava 7,4\% (NARDI; SAPATA; LOPES, 2013). Quanto à expectativa de vida no município, até 0 ano 2010 estimava-se em 76,1 anos, um aumento comparado à expectativa de 68,5 anos em 1991 (ATLAS BRASIL, 2013).

Concernente a esse contexto, é no cotidiano da cidade que as manifestações de dominação e apropriação são construídas e praticadas, produzindo o território e as territorialidades cotidianas, condição e produto do processo de territorialização (SAQUET, 2013). Esse cotidiano pode ser analisado a partir de duas formas, sendo: do alto e do chão (CERTEAU, 2014). A visão do alto coloca-se a distância ou proporciona uma visão de sobrevoo (SOUZA, 2013). Essa é a visão da administração urbana, das estratégias econômicas e políticas implantadas - muitas vezes também a mais divulgada - e é dela que partem as decisões tomadas com relação ao espaço urbano (CERTEAU, 2014). Em contraponto, conforme o mesmo autor, a visão do chão acessa 0 olhar do homem ordinário, com suas práticas inventadas, trajetórias e histórias anônimas. É a partir das práticas e dos usos desse homem ordinário que se enxerga aquilo que passa por invisível na cidade.

Nesse sentido, a discussão proposta nessa pesquisa fundamenta-se na visão do cotidiano a partir do chão, integrando essa visão com as abordagens sobre territórios, descobrindo as práticas singulares que constituem o cotidiano do homem ordinário, no caso os idosos que se apropriam e utilizam os aparelhos das ATls. Adotando a perspectiva de Certeau (2014), julgou-se pertinente compreender como ocorre a territorialização do cotidiano dos moradores de um determinado bairro a partir da produção do espaço urbano por meio de intervenções governamentais com a implantação das ATls.

Diante disso, defende-se que combinar as abordagens de intervenção governamental, por meio da produção do espaço urbano, ampliada à perspectiva de territorialização e cotidiano, pode trazer contribuições teóricas e empíricas relativas à temática aqui tratada. Inserindo-se nos contextos territoriais, os Estudos Organizacionais buscam compreender as especificidades das organizações locais, envolvendo os agentes sociais e as suas ações, que produzem e reproduzem o espaço urbano nos territórios. Quanto ao cotidiano, busca-se tornar visíveis os microprocessos sociais dos indivíduos, colocando-os no acontecer da história, assim como analisar as influências das forças hegemônicas sobre as populações locais, evidenciando o impacto dessas pressões na relação dos indivíduos (LEVIGARD; BARBOSA, 2010). Para tanto, optou-se por estudar esse fenômeno por intermédio dos idosos que fazem a apropriação-uso das ATls, especificamente na Vila Santo Antônio, em Maringá-PR.

Para alcance do objetivo proposto, partiu-se das discussões sobre a produção do espaço urbano, território e territorialização e cotidiano, que serviram como fundamento para realização da presente pesquisa. Em seguida, são expostos os procedimentos metodológicos, seguidos dos resultados e das considerações finais.

\section{SOBRE A PRODUÇÃO DO ESPAÇO URBANO}

O espaço urbano de uma cidade é compreendido a partir do conjunto de diferentes usos de terra sobrepostos entre si, diferenciando áreas e organizando espacialmente a cidade, com base em sua função, sendo um espaço articulado e fragmentado (CORRÊA, 2004). Conforme o autor, o espaço urbano é dito, ainda, como reflexo da sociedade e condicionante social, que assume uma dimensão simbólica e surge como campo de lutas e conflitos sociais. Nesse sentido, o espaço urbano representa toda a organização política, econômica e social, assim como o modo de vida caracterizante das cidades, não restringindo sua compreensão somente ao espaço físico (COELHO, 2012).

Revista Alcance - Eletrônica - vol. 25 - n. 1 - Jan./Abr. 2018 
Complementarmente, os diferentes usos da terra que compõem o espaço urbano ocorrem conforme 0 movimento da própria sociedade, de suas estruturas sociais e funções urbanas demandadas que se materializam nas formas espaciais, simultaneamente produzidas por agentes sociais (SANTOS, 1994). Nesse contexto, o espaço urbano é um produto social resultante de ações acumuladas por meio do tempo, preconcebidas por aqueles que produzem e consomem esse mesmo espaço. Dito de outra forma, são agentes sociais que atuam diante da acumulação de capital, manutenção das relações de produção e constante processo de reorganização espacial conforme seus interesses (CORRÊA, 2004).

Os proprietários dos meios de produção, sobretudo os grandes industriais, os proprietários fundiários, os promotores imobiliários, o Estado e os grupos sociais segregados e excluídos são os agentes sociais, que por meio de estratégias e ações concretas produzem o espaço urbano (CORRÊA, 2004). Congruente a Corrêa (2004), observam-se os sujeitos da produção do espaço apontados por Carlos (2013), ao também considerar o Estado e os sujeitos sociais com suas necessidades e interesses, assim como o capital, em referência ao industrial, comercial, financeiro e mercado mobiliário.

As ações desses agentes sociais não ocorrem de forma neutra, conforme afirma Lefebvre (2000). Os agentes que compõem os grupos providos de poder, especificamente, agem sistematicamente e intencionalmente para (re)inventar racionalmente o espaço social, os quais são refletidos pelo seus interesses dominantes, marcados por suas ideologias, estratégias e políticas (LEFEBVRE, 2000). Carlos (2013) considera que o espaço urbano é constituído das relações sociais, condições da vida cotidiana e o modo como a sociedade se apropria desse espaço.

Todavia, dentre todos os agentes sociais, o Estado é aquele que desfruta de instrumentos mais amplos na produção do espaço (COELHO, 2012), interligando-se com os demais agentes, tanto quanto elaborando leis e normas (CORRÊA, 2004). O Estado desempenha, então, diversos papéis na produção do espaço, posto que o mesmo atua como "grande industrial, consumidor do espaço e de localizações específicas, proprietário fundiário e promotor imobiliário, sem deixar de ser também um agente de regulação do uso do solo e 0 alvo dos chamados movimentos sociais urbanos" (CORRÊA, 2004, p. 24).

Diante disso, conforme destacado por Carlos $(2013$, p. 66), a produção do espaço urbano, em sua dimensão prática socioespacial, é revelada a partir do cotidiano de todos os agentes sociais, do "modo como se produz o espaço da vida nos modos de apropriação-uso que a sociedade faz do espaço como momento de sua produção". Consequentemente, da utilização desse mesmo espaço ocorre a sua reprodução, revelada em suas dimensões material (dimensão física), concreta (relações sociais) e abstrata (apropriação, usos, cotidiano, valor de uso - valor de troca) (CARLOS, 2013).

Cabe compreender, contudo, que da produção do espaço há a produção da cidade, sendo a cidade 0 espaço de conflitos entre os agentes sociais, com seus interesses por detrás da produção do espaço urbano (CORREAA, 2013). Desses interesses, Corrêa (2013) chama a atenção para as estratégias do Estado, que por meio de intervenções urbanas concebem prioridade aos seus próprios interesses. Complementarmente, Harvey (2005) considera que tais estratégias, por detrás desses interesses, decorrem do empresariamento urbano, visando à melhoria das atividades, do poder público, voltadas para as cidades, de forma a buscar 0 desenvolvimento urbano e capitalista (HARVEY, 1996).

Portanto, por ser condicionante social, os espaços antes considerados resultado de uma produção social, a partir de relações sociais, passam, então, por um lado, a serem transformados em produtos de troca em decorrência da apropriação privada que surgem com a urbanização (CARLOS, 1996; CORRÊA, 2004). Por outro lado, o espaço urbano também é produtor, compreendido por meio das forças produtivas, do conhecimento, da divisão do trabalho e do Estado, assim como dos agentes que o moldam (CORRÊA, 2004). Contudo, mais complexo que compreender o espaço como um produto, é compreender como os movimentos, os ritmos, as reconstruções e as reproduções são produzidos, garantindo as estratégias dos pequenos e dos grandes agentes sociais (CORREAA, 2004; SHIMADA, 2015).

Diante disso, faz-se necessária a compreensão do espaço em sua realidade de constante transformação por meio da apropriação-uso. Desse movimento de transformação emergem os territórios e, consequentemente, os processos de territorialização. 


\section{SOBRE TERRITÓRIOS E TERRITORIALIZAÇÃO}

A compreensão sobre territórios parte da distinção entre espaço e território, visto que não são termos equivalentes (RAFFESTIN, 1993), sendo o espaço anterior ao território, que, por sua vez, se efetiva diante das relações sociais (CANDIOTTO; SANTOS, 2009). Cabe observar que a compreensão sobre território apresenta variações ao longo da história. As discussões sobre o assunto ganharam destaque com Ratzel no campo da Geografia Política, especialmente em temas relacionados às políticas de dominação de determinada porção de terra apropriada por um grupo, referindo-se muitas vezes ao Estado (CANDIOTTO; SANTOS, 2009). No decurso do tempo, Raffestin (1993) buscou debater território e poder, avançando a compreensão de território para além de Estado-nação, sistematizando uma Geografia do Poder. Conforme Raffestin (1993), todo trabalho, energia, informação e significado produzido em uma parcela do espaço transforma-o em um território construído e apropriado.

No âmbito das discussões brasileiras, em um contexto de materialidade/imaterialidade, os estudos de Milton Santos, Marcos Saquet, Rogério Haesbaert e Marcelo Lopes de Souza contribuíram para o avanço sobre a abordagem territorial (CANDIOTTO; SANTOS, 2009; SAQUET, 2013). Santos (1994) trouxe uma perspectiva materialista, em favor do espaço geográfico, considerando o mesmo como composto de objetos e ações, por meio da coexistência de diversos territórios materiais e imateriais. Além disso, o território carrega configurações históricas, reveladas, por meio de objetos e ações, do passado e do presente, herdadas pela sociedade (SANTOS; SILVEIRA, 2006).

Saquet (2013), por sua vez, destacou a interdependência entre espaço e território, considerando ambos indissociáveis. Para 0 autor, o território é produzido junto às relações de poder desenvolvidas por determinado grupo social e efetivadas em diferentes escalas - as territorialidades cotidianas -, sendo condição e produto do processo de territorialização. As territorialidades são a expressão subjetiva e coletiva da apropriaçãouso dos territórios. Para Coimbra e Saraiva (2013, p. 35), a territorialidade consiste "em uma ação apropriativa de um determinado espaço por um indivíduo ou um grupo de indivíduos que desenvolvem, em relação a um objeto ou símbolo, uma relação de posse" e o território, nesse sentido, configura-se como a expressão espacial de tais relações (SOUZA, 2009). Desse modo, compreende-se que as ações locais e as forças externas, advindas da dinâmica política, econômica e cultural, determinam os territórios, que estão em movimentos e podem ser temporários ou permanentes (SAQUET, 2013). Quanto à territorialização, entende-se como um sinônimo da organização territorial, como a "ação, movimento ou processo de construção e criação de territórios pela apropriação, uso, identificação, enraizamento com determinadas extensões do espaço por lógicas políticas, econômicas ou culturais" (FUINI, 2014, p. 233).

Já Haesbaert (2012) destacou o poder nas discussões sobre território e propôs uma abordagem integradora, reunindo e combinando a dimensão econômica (recursos naturais e seus usos), política (relações de poder) e cultural (identidade). Conforme apontado pelo autor, o território, como espaço de dominação e apropriação, é compreendido a partir de um continuum da dimensão simbólica-cultural (apropriação subjetiva) a uma dimensão concreta-funcional (dominação político-econômica). Nessa perspectiva, o território é simultaneamente funcional e simbólico, uma vez que há uma indissociabilidade entre a realização de suas funções e a produção de seus significados. A construção efetiva do território insere-se num sentido simbólico e é definida em referência às relações culturais (HAESBAERT, 2004; 2007b). A materialização da territorialidade não é imprescindível para que a territorialização ocorra. Embora todo território seja dotado de uma territorialidade, nem toda territorialidade exige um território no seu sentido material (HAESBAERT, 2009).

Diante das relações de poder e estratégias que ocorrem entre sociedade e espaço, o território é construído, o que Haesbaert (2004) considera como territorialização, seja por meio de dominação ou apropriação, atribuindo significados e, consequentemente, efetivados pelas relações de pertencimento (comportamentos, práticas, linguagens, dentre outras) de forma a estabelecer um território.

Souza (2000, p. 96), ainda no plano das discussões brasileiras, afirma que território é um "espaço definido e delimitado por e a partir de relações de poder". Para o autor, é insuficiente a compreensão de território somente atrelado ao Estado-nação, visto que os "territórios são construídos e desconstruídos" em diferentes escalas espaciais e temporais, reafirmando o movimento desreterritorialização. 0 autor considera, ainda, que a compreensão de territórios deve ser considerada para a formulação de estratégias de desenvolvimento socioespacial, atribuindo importância à territorialidade. A territorialidade, assim, reflete distintos aspectos do que é vivido em um dado território pelos membros de uma coletividade (SARAIVA; CARRIERI; SOARES, 2014).

Tendo em vista, contudo, as abordagens dos autores referenciados, observa-se que a compreensão de territórios avança além da delimitação física e constitui-se ainda das relações de poder efetivadas em 
determinadas áreas. Essas mesmas relações são influenciadas pela comunicação e pela identidade dos sujeitos e dos grupos sociais, abarcando a dimensão material e simbólica. Conforme apontam Candiotto e Santos (2009), o território, tanto quanto o espaço, é produzido por ações e objetos e pelo material e imaterial, componentes-chave para a concretização, apropriação e dominação do território. Além disso, seja o Estado ou qualquer outro agente social, todos produzem territórios de acordo com seus interesses e estratégias.

Assim sendo, a conquista de um território envolve também a conquista de uma nova identidade ou novas relações. $O$ território precisa conciliar a identificação de sujeitos e ações em um mesmo espaço, uma vez que ele é, de início, um espaço cultural de identificação ou de pertencimento e a sua apropriação só acontece em um segundo momento (MEDEIROS, 2009). Dessa forma, estudos mais atuais já reconhecem que os territórios são mais marcados por um movimento contínuo, uma dinâmica construída socialmente, do que por sua fixação em uma terra específica, uma representação estática natural (VALVERDE, 2004; SARAIVA; CARRIERI; SOARES, 2014; TEIXEIRA; SARAIVA; CARRIERI, 2015).

Para tanto, adotou-se a compreensão de que o espaço, como territorializado, é um campo que remete às territorialidades e aos movimentos cotidianos dos agentes sociais. É no cotidiano, ou seja, no espaço construído e praticado, que se percebem as manifestações de dominação e apropriação. Por isso, faz-se necessária a compreensão do cotidiano, abordada a seguir, especialmente pelas lentes de Michel de Certeau.

\section{A RESPEITO DO COTIDIANO}

Existem diversas perspectivas que abordam o cotidiano, compreendendo-o além da rotina dos acontecimentos, e como um instrumento de conhecimento e análise da realidade social, evidenciando a dinâmica dos processos de acomodação e mudança social (LEVIGARD; BARBOSA, 2010). Dentre essas perspectivas, destacam-se as contribuições de Henri Lefebvre, Agnes Heller e Michel de Certeau. Porém, para realização da presente pesquisa, o foco foi dado para a perspectiva de Michel de Certeau, especificamente em sua obra principal $A$ Invenção do Cotidiano, dividida em dois volumes.

Nesse sentido, cabe observar, primeiramente, que o cotidiano aqui é compreendido como (CERTEAU; GIARD; MAYOL, 2013, p. 31):

[...] aquilo que nos é dado cada dia (ou que nos cabe em partilha), nos pressiona dia após dia, nos oprime, pois existe uma opressão no presente. [...] 0 cotidiano é aquilo que nos prende intimamente, a partir do interior. É uma história a meio-caminho de nós mesmos, quase em retirada, às vezes velada. [...].

Diante disso, considerando a compreensão do termo cotidiano, observa-se que Certeau parte da habilidade de acreditar no mais fraco, o homem ordinário que se movimenta taticamente diante das estratégias do forte. A atenção é voltada para o sujeito social considerado passivo pelo mercado e muitas vezes esquecido no âmbito do consumo, especialmente por estar inserido em uma sociedade economicamente capitalista direcionada para o poder centralizador da classe dominante (GIARD, 2014). Baseando-se nessa compreensão, Certeau volta-se para a forma como esse homem ordinário (o usuário) apropria-se ou reapropria-se, por meio de suas diferentes maneiras de fazer, daquilo que the é oferecido, ou seja, as suas operações e os seus usos individuais. Trata-se, portanto, "de esboçar uma teoria das práticas cotidianas para extrair do seu ruído as maneiras de fazer", muitas vezes denominadas como resistências (GIARD, 2014, p. 16).

As maneiras de fazer referem-se às "mil práticas pelas quais os usuários se reapropriam do espaço organizado", apontadas como táticas, ou seja, a forma como o usuário ressignifica as estruturas ou os modelos de consumo, modificando e criando o seu próprio cotidiano (CERTEAU, 2014, p. 33). Cabe destacar que Certeau (2014) busca mostrar o que é invisível nesse cotidiano, isto é, os movimentos e as trajetórias sutis do homem ordinário.

Para tanto, Certeau (2014) distingue as práticas entre táticas e estratégias, posto que essas práticas são realizadas diante das relações de poder e forças presentes no espaço. As estratégias remetem à habilidade de produzir e impor uma ordem, aquilo que é formalmente estabelecido, assim como Certeau $(2014$, p. 93) conceitua que: 
[...] o cálculo (ou a manipulação) das relações de forças que se torna possível a partir do momento em que um sujeito de querer e poder (uma empresa, um exército, uma cidade, uma instituição científica) pode ser isolado. A estratégia postula um lugar suscetível de ser circunscrito como algo próprio e ser a base de onde se podem gerir as relações com uma exterioridade de alvos ou ameaças (os clientes ou os concorrentes, os inimigos, o campo em torno da cidade, os objetivos e objetos da pesquisa, etc.) [...].

Contrariamente às estratégias, as táticas são trajetórias indeterminadas, que circulam entre as brechas de uma ordem estabelecida, as quais são marcadas pela ausência do poder dominador (CERTEAU, 2014). Conforme Certeau (2014, pp. 94-95) a tática é uma

[...] ação calculada que é determinada pela ausência de um próprio. Então, nenhuma delimitação de fora lhe fornece a condição de autonomia. A tática não tem por lugar senão 0 do outro. E por isso deve jogar com o terreno que lhe é imposto tal como o organiza a lei de uma força estranha. [...]. Aproveita as "ocasiões" e delas depende, sem base para estocar benefícios, aumentar a propriedade e prever saídas.

As táticas constituem de muitas práticas cotidianas, como: falar, ler, circular, fazer compras, cozinhar, dentre outras, identificadas por Yilmaz (2013) como um ato de resistência, não planejadas, decorrentes dessas práticas cotidianas. Conforme Yilmaz (2013), a invenção do cotidiano emerge dessas táticas do homem ordinário, que desenvolve diariamente e criativamente suas lutas silenciosas, sem a intenção de conquistar status ou interromper algum contrato social imposto (SOUZA FILHO, 2002; SHIMADA, 2015). A estratégia advém de uma ordem postulada de um poder, por essa razão possui um lugar próprio, delimitado e estável. Já a tática é dependente do tempo e do contexto, utilizando esse lugar próprio para (re)inventar um espaço para si mesmo, sendo esse espaço um lugar praticado e produzido, fruto das dinâmicas de movimentos ou operações dos indivíduos ou grupos (CERTEAU, 2014).

Ainda a respeito do cotidiano, Certeau, Giard e Mayol (2013) observam as práticas culturais dos usuários da cidade no espaço do seu bairro. As táticas moldam a noção de bairro, posto que "o usuário sempre consegue criar para si algum lugar de aconchego, itinerários para o seu uso ou o seu prazer, que são as marcas que ele soube, por si mesmo, impor ao espaço urbano" (CERTEAU; GIARD; MAYOL, 2013, p.42). Observa-se, então, que o bairro é um espaço social que evidencia os elementos do cotidiano, organizados conforme dois registros: os comportamentos e os benefícios simbólicos que se espera obter. Complementarmente, verifica-se a regulação da conveniência, um contrato implícito, articulando esses dois registros, ou seja, a contribuição de cada um para que seja possível a vida cotidiana (CERTEAU; GIARD; MAYOL, 2013).

Dessa forma, tendo como base a compreensão da produção do espaço urbano, o processo de territorialização e o cotidiano por meio das práticas que o constitui e a propensão do homem ordinário para inventividade e criatividade, buscou-se tornar evidentes as ações desse homem ordinário, as suas maneiras de fazer e sua (re)apropriação do espaço, muitas vezes não percebidas diante normas e formalidades impostas aos mesmos.

\section{PROCEDIMENTOS METODOLÓGICOS}

Para alcance do objetivo proposto, buscou-se o caminho da pesquisa qualitativa, com caráter descritivo, visto que houve a preocupação em manter uma aproximação com a realidade social das pessoas investigadas, explorando seus comportamentos e experiências, descrevendo-os com exatidão (DENZIN; LINCOLN, 2006). Além disso, adotando Certeau (2014) e Certeau, Giard e Mayol (2013) como base conceitual para a compreensão do cotidiano, fez-se necessária a pesquisa qualitativa, visto que se buscou entender como as práticas do cotidiano ocorrem no "subsolo", especificamente como as intervenções urbanas implementadas, por meio das ATls, configuram o cotidiano das pessoas idosas que as frequentam, e não com um olhar totalizante e a distância da realidade.

Nesse sentido, no primeiro momento, a pesquisa documental foi realizada por meio de material gráfico e informativo divulgado pela Prefeitura de Maringá, bem como por meio do website da Prefeitura para obter informações iniciais sobre as ATIs, incluindo a identificação da localização das mesmas. No segundo momento,

Revista Alcance - Eletrônica - vol. 25 - n. 1 - Jan./Abr. 2018 
12 entrevistas individuais foram realizadas por meio de um trabalho de campo no mês de janeiro de 2017. 0 roteiro de entrevista contemplou aspectos quanto ao uso do espaço anterior e posteriormente à construção da ATI; razões para iniciar e continuar a frequentar o espaço da ATI; a convivência e as expectativas quanto ao mesmo espaço. Buscou-se realizar as entrevistas em momentos diferentes, considerando os horários em que os usuários frequentavam a ATI, tanto no início da manhã (das $7 \mathrm{~h}$ às $10 \mathrm{~h}$ ), quanto no final da tarde (18h às 19h30min). A escolha dos sujeitos para fazer parte do corpus de entrevistas, conforme caracterização exposta no Quadro 1, decorreu de três critérios preliminares, a saber: ter idade igual ou superior a 60 anos, ou seja, pessoas idosas, conforme o Estatuto do Idoso (Lei n. 10.741, 2003) (BRASIL, 2003); praticar exercícios físicos na ATI semanalmente; e residir no bairro escolhido. $O$ bairro escolhido foi a Vila Santo Antônio, onde está localizada a $14^{\text {a }}$ ATI do município, inaugurada em julho de 2007. A ATI está instalada na praça da igreja do bairro, que contém também uma quadra de esportes e playground, assim como lojas comerciais no entorno.

Quadro 1: Caracterização dos entrevistados

\begin{tabular}{|c|c|c|c|c|c|c|c|}
\hline Entrevistado & Sexo & $\begin{array}{c}\text { Tempo de } \\
\text { moradia }\end{array}$ & Idade & Ocupação & $\begin{array}{c}\text { Estado } \\
\text { civil }\end{array}$ & $\begin{array}{c}\text { Frequenta } \\
\text { ATI }\end{array}$ & $\begin{array}{c}\text { Frequenta ATI da } \\
\text { VSA }^{*}\end{array}$ \\
\hline E1 & Feminino & 40 anos & 78 & Aposentada & Viúva & 9,5 anos & 9,5 anos \\
\hline E2 & Feminino & 12 anos & 81 & Aposentada & Viúva & 9,5 anos & 9,5 anos \\
\hline E3 & Feminino & 40 anos & 71 & Aposentada & Casada & 9,5 anos & 9,5 anos \\
\hline E4 & Feminino & 43 anos & 83 & Aposentada & Viúva & 10 anos & 9,5 anos \\
\hline E5 & Masculino & 1,5 ano & 60 & Motorista & Casado & 10 anos & 1,5 ano \\
\hline E6 & Masculino & 40 anos & 72 & Aposentado & Casado & 9,5 anos & 9,5 anos \\
\hline E7 & Masculino & 2 anos & 83 & Aposentado & Viúvo & 1 ano & 1 ano \\
\hline E8 & Feminino & 29 anos & 76 & Aposentada & Viúva & 9,5 anos & 9,5 anos \\
\hline E9 & Masculino & 6 anos & 65 & Aposentado & Casado & 10 anos & 6 anos \\
\hline E10 & Feminino & 9 anos & 64 & Aposentada & Viúva & 8 anos & 8 anos \\
\hline E11 & Masculino & 1 mês & 65 & Aposentado & Casado & 8 anos & 1 mês \\
\hline E12 & Feminino & 30 anos & 74 & Aposentada & Viúva & 6 anos & 6 anos \\
\hline
\end{tabular}

Fonte: Trabalho de campo, 2017

*VSA: Vila Santo Antônio

No que concerne à análise dos dados, realizou-se uma interpretação geral sobre as informações obtidas e produzidas durante a pesquisa documental e de campo. Para tanto, utilizou-se como instrumento a análise de conteúdo (BARDIN, 1979), tanto para organização dos documentos como para compreensão das falas dos sujeitos que participaram da investigação. Destaca-se que as categorias temáticas foram definidas após a coleta dos dados. Observa-se que as mesmas emergiram a partir das falas dos entrevistados, que foram guiadas pelo roteiro de entrevistas previamente elaborado com base nas teorias apresentadas. Para melhor compreensão das discussões dos resultados, alguns trechos das entrevistas foram transcritos e identificados com códigos, como E8; P.14; L.22-30, o que se refere à transcrição da entrevista 8, na página 14, entre as linhas 22 e 30.

\section{RESULTADOS}

A análise dos resultados foi organizada de forma a atender a proposta da pesquisa, apresentando as categorias identificadas com base nas entrevistas. A partir da análise dos documentos, fez-se necessário compreender a visão da Prefeitura quanto às ATls. A intenção não foi de comparar as duas visões, mas contextualizar brevemente a visão do alto, ou seja, da administração urbana, para compreender a visão dos idosos que praticam os exercícios físicos na ATI da Vila Santo Antônio, ou seja, a visão do chão.

\subsection{A PROPOSTA DA ACADEMIA DA TERCEIRA IDADE (ATI)}

"Melhor, só se inventarem o elixir da juventude".

"Uma revolução no conceito de promoção da saúde".

Os trechos acima são apresentados na capa do material gráfico, sobre a ATI, divulgados pela Prefeitura de Maringá. Os materiais gráfico e informativo da ATI, escritos por Palácios e Nardi (2009), que atuam 
na Secretaria Municipal de Saúde de Maringá, podem ser acessados no site da Prefeitura de Maringá e no Portal Saúde Maringá. Ambos os materiais, além dos trechos apresentados, definem a ATI como uma academia instalada ao ar livre e constituída por dez aparelhos de ginástica diferentes, permitindo ao usuário realizar exercícios de alongamento, fortalecimento, desenvolvimento da musculatura e aeróbico. Resultados que são garantidos para quem frequenta a academia semanalmente durante 30 minutos, sentindo-se mais disposto para realização de suas atividades diárias.

Além disso, assim como consta no material informativo, os usuários podem contar com profissionais do Programa Saúde da Família, que os acompanham periodicamente, orientando e contribuindo com a promoção da saúde por meio da atividade física. Os monitores atuam nos períodos matutinos, das $7 \mathrm{~h}$ às $10 \mathrm{~h}$, e no período vespertino/noturno, das $17 \mathrm{~h} 30 \mathrm{~min}$ às $20 \mathrm{~h} 30 \mathrm{~min}$, detectando a glicemia capilar e verificando sinais vitais dos usuários da ATI, com o objetivo de monitorar a saúde dos mesmos, especialmente aqueles que são considerados hipertensos e diabéticos.

A ideia, que surgiu nas praças de Pequim, na China, tem como objetivo "incentivar, principalmente entre os idosos, a prática regular de atividade física, a socialização, a melhora da autoestima e da saúde em geral" (PALÁCIOS; NARDI, 2009, p. 3). Após o pioneirismo maringaense, resultado de uma parceria públicoprivada, diversas cidades no país desenvolveram a mesma estratégia, que tem apoio do Ministério da Saúde e dos Esportes. Em Maringá, somam-se, atualmente, 62 unidades da ATI (SECRETARIA MUNICIPAL DE ESPORTES E LAZER, 2017).

Segundo informações contidas nos materiais, o projeto da ATI é inovador e pioneiro no Brasil, desenvolvido como uma das estratégias do Programa Maringá Saudável (PMS), de forma a proporcionar qualidade de vida e saúde à população. Torna-se importante ressaltar que, em 2005, o município de Maringá ingressou na Rede de Municípios Potencialmente Saudáveis, ligada à UNICAMP (Universidade Estadual de Campinas), IPES (Instituto de Pesquisas Especiais para a Sociedade) e OPAS/OMS (Organização PanAmericana da Saúde/Organização Mundial da Saúde). De forma a seguir as estratégias de Municípios e Comunidades Saudáveis da OPAS/OMS, no mesmo ano foi criado o Grupo de Trabalho Intersetorial (GTI), com representantes das secretarias municipais. Como objetivo de trabalho do GTI, planejamento e desenvolvimento de ações de promoção da saúde foram estabelecidos, especialmente projetos na área da atividade física, alimentação saudável e combate ao tabagismo, denominando o PMS, anteriormente citado.

Diante desse contexto, a proposta da ATI foi desenvolvida de forma a incorporar ações de promoção de saúde e qualidade de vida por meio da atividade física, uma vez que as principais causas de morbidade hospitalar no município são atribuídas às doenças do sistema respiratório e do sistema circulatório, transtornos mentais e neoplasias; assim como as principais causas de mortalidade, acrescentando as doenças endócrinas e metabólicas (PALÁCIOS; NARDI, 2009).

Como resultados, representantes da prefeitura verificam que a proposta da ATI alcança o objetivo, posto que teve aceitação positiva por parte da população, em especial os idosos portadores de doenças crônicas (PALÁCIOS; NARDI, 2009). Aliado a isso, a prática da atividade física está contribuindo com a prevenção de doenças e proporcionando qualidade de vida aos usuários e reduzindo os custos sociais, internações hospitalares e mortalidade. Para esses representantes, é o começo da "superação de uma fase em que a doença e os sintomas deixam de ser o centro das atenções, para outra, que passa a ter o ser humano e a 'saúde', [...] como foco principal das ações do poder público" (PALÁCIOS; NARDI, 2009, p. 6).

\subsection{DE UM ESPAÇO SEM USO A UM ESPAÇO TERRITORIALIZADO}

Inaugurada em julho de 2007, a ATI ocupa um espaço que antes era abandonado e sem uso para os moradores do bairro. A construção da ATI na Vila Santo Antônio foi acompanhada de um projeto de revitalização da praça em que a mesma está localizada. Dentre os reparos realizados, a ATI foi instalada ao lado da quadra de esporte e do playground.

Por meio das entrevistas foi possivel perceber que grande parte da população não tinha conhecimento da construção da ATI. Por mais que essa intervenção tenha sido recebida de forma positiva, somente uma entrevistada relatou que participou das assinaturas do abaixo-assinado para a construção da academia, conforme relato: 
Tinha a quadra [de esportes] e o parque [playground] [...]. Acho que o parque era mais para cá e passaram para lá. [...]. Tiraram um pedacinho daquela quadra lá [playground] e fizeram isso aqui [a ATI], mas foi por um abaixo assinado mesmo, que o povo pediu. É que na hora que começou queria que eles fizessem aqui. (E8; P.14; L.22-30).

Até a realização da entrevista em questão, nenhum entrevistado havia mencionado 0 abaixoassinado. Os demais entrevistados, em sequência à oitava entrevista, também não relataram esse acontecimento, uma vez que os mesmos narraram que tiveram conhecimento no dia da inauguração da ATI. Verifica-se aqui a movimentação da sociedade para a produção do espaço urbano, envolvendo os agentes sociais que contribuem para o processo de reorganização espacial, como no caso da ATI, isto é, a renovação urbana que impacta em mudanças sociais e econômicas do município (SANTOS, 1994; CORRÊA, 2004).

A ideia da ATI foi recebida de forma positiva pelos moradores do bairro que não participaram desse movimento e processo de reorganização urbana, uma vez que, segundo relatos, a ATI proporciona mais conforto e comodidade para a prática dos exercícios físicos, assim como é de fácil acesso para os moradores do bairro. A academia acabou com a falta que os moradores sentiam da prática de exercícios físicos. Alguns frequentavam as aulas de alongamento que eram realizadas no salão da igreja e foram extintas um ano antes da construção da ATI, após o início da gestão municipal da época. Outros, ainda, frequentavam a ATI do bairro vizinho para realizar os exercícios.

Considerada como um incentivo para sair de casa e como uma forma de suprir a necessidade de pagar academias particulares, a ATI é considerada, pelos entrevistados, como um dever do Estado, sendo este um retorno do imposto pago pelo contribuinte do município. Existem no Brasil diversos documentos legais que garantem os Direitos da Pessoa Idosa, como: a Política Nacional do Idoso, Lei Orgânica da Assistência Social, Estatuto do Idoso, Política Nacional de Saúde do Idoso e Carta de São José sobre os direitos dos idosos na América Latina e Caribe. Especificamente no Estatuto do Idoso (Lei n. 10.741, 2003) (BRASIL, 2003), é dever não somente da família e da sociedade, mas do Poder Público, assegurar, dentre todos os direitos, o acesso ao esporte e ao lazer e a convivência comunitária. Verificou-se que alguns moradores têm conhecimento desse direito, e é dessa forma que compreendem a construção da ATI. Isso fica claro na passagem em que um dos entrevistados afirma: "Aqui você não paga nada, mas é o investimento dos impostos que a gente paga. É o dever deles [Prefeitura] fazer. Porque eles não são donos da cidade, eles são funcionários" (E5; P.11; L.94-96).

Infere-se, contudo, que as forças do poder público e de alguns agentes locais específicos atuaram na produção do espaço urbano utilizado para a instauração da ATI, particularmente na Vila Santo Antônio. A partir das relações de poder e da demanda social, o espaço agora territorializado é transformado em um espaço de prática de exercícios físicos, atendendo aos direitos e aos deveres públicos, assim como a demanda social da população, como o envelhecimento populacional, que pode resultar no aumento de índice de doenças crônicas e, consequentemente, no aumento de custos (HAESBAERT, 2012; SAQUET, 2013). Ademais, as territorialidades cotidianas que expressam a apropriação e o uso desse território, por meio das relações efetivas, da atribuição de significados e do sentimento de pertencimento podem ser mais bem compreendidos no decorrer da análise.

\subsection{SAÚDE E QUALIDADE DE VIDA PROPORCIONADAS PELA PRÁTICA DOS EXERCÍCIOS FíSICOS NA ATI}

A qualidade de vida é anunciada desde os discursos dos representantes da Prefeitura às falas dos moradores da Vila Santo Antônio e usuários assíduos da ATI. O espaço, agora apropriado pelos moradores, é atribuído como um meio para manter-se saudável e prevenir doenças, assim como acabar com o estresse diário provocado pela ociosidade. Tornaram-se salientes nos relatos dos entrevistados os benefícios proporcionados por meio das práticas da atividade física na ATI. Dentre todos os citados, destacam-se a flexibilidade do corpo, a redução e a supressão de dores corporais, melhoras no condicionamento físico e disposição, melhora na locomoção e na coordenação motora, manutenção do peso, elevação da autoestima e prevenção para a depressão, tudo realizado conforme o limite de cada pessoa, como é possível identificar na seguinte afirmação:

Ela [a ATI] melhora bem a locomoção, melhora até o ânimo, o preparo físico, o estresse. Ah, por exemplo, dizendo a verdade, dá até autoestima na gente, e a gente precisa fazer exercício. A gente só fazer caminhada e trabalhar não faz os músculos. Aqui é bom que você mexe com o corpo todo. (E.5; P.10; L.15-18). 
No mesmo sentido, devido aos benefícios comprovados cientificamente por pesquisas das áreas de saúde e esporte, que a prática dos exercícios físicos, não somente na ATI, reduz o risco de doenças crônicas (diabetes e hipertensão), obesidade, doenças cardíacas e alguns tipos de câncer, médicos recomendam a frequência na ATI. O tratamento de algumas doenças, dentre as mais citadas pelos entrevistados como artrose, ácido úrico, colesterol e hipertensão, conciliado com as atividades físicas é mais eficaz, reduz o consumo de remédios em alguns casos.

Observa-se que a produção do espaço avançou os aspectos materiais, englobando aspectos simbólicos que agora constituem as falas daqueles que se apropriaram e utilizam a ATI. O discurso que antes era expresso por parte da Prefeitura para o incentivo dos exercícios físicos ganhou força e passou a ser recorrente nos relatos de quem se beneficia com a academia, divulgando e incentivando demais pessoas a frequentarem e praticarem a atividade física; assim, como outros segmentos da sociedade, em especial da área da saúde, que também incentivam e promovem os benefícios da ATI.

Nesse contexto, depreende-se que a saúde e a qualidade de vida, vivenciadas pelos frequentadores da ATI no bairro em questão, resultam da forma como esses usuários se apropriam desse espaço reservado, revelado a partir de seu cotidiano. Conforme já ressaltado por Carlos (2013), essa apropriação resultou na reprodução desse espaço, abrangendo o uso cotidiano desses frequentadores, bem como os diferentes aspectos vivenciados coletivamente e suas relações de convivência, refletidos pela territorialidade (SARAIVA; CARRIERI; SOARES, 2014).

Ademais, afirmar-se que, utilizando-se de estratégias para resolução de questões que implicam aspectos econômicos, como gastos com saúde pública advindos do envelhecimento populacional, a Prefeitura do Município de Maringá usufruiu de uma combinação de instrumentos, refletidos a partir de seus interesses quanto ao equilíbrio social, econômico e espacial, para a produção do espaço urbano, que trouxe melhorias para a população. Da mesma forma, na visão dos usuários, quem não frequenta a ATI é acomodado e não se preocupa com a saúde, um reflexo do discurso oficial da Prefeitura, que é propagado pelos mesmos como um meio de proporcionar saúde e qualidade de vida.

\subsection{APROPRIAÇÃO E A INVENTIVIDADE NA PRÁTICA DOS EXERCÍCIOS FíSICOS}

As instruções quanto ao uso de cada aparelho foram inicialmente orientadas por monitores contratados pela Prefeitura, em parceria com Instituições de Ensino Superior do município, conforme relatos dos entrevistados. Nos dois primeiros anos, os usuários da ATI contaram com o auxílio desses monitores, que após esse período não estiveram mais presentes na ATI. Devido a esse acontecimento, não foram todos os usuários que receberam as instruções para a prática dos exercícios físicos com os aparelhos da academia. Aqueles que já moravam no bairro, nos primeiros anos após a inauguração da academia, puderam aproveitar as instruções dos monitores na ATI da Vila Santo Antônio. Há, ainda, outros entrevistados que aprenderam a utilizar os aparelhos em outras ATIs, como em bairros vizinhos ou em ATIs de outras cidades, ou até mesmo no Centro de Medicina Preventiva, de um dos parceiros privados da prefeitura - Unimed Maringá -, no caso daqueles que possuem o convênio. Esse cenário é relatado por uma das entrevistas:

Quando eu comecei lá embaixo [no bairro vizinho] tinha uma professora que estudava e deu umas aulas. [...]. Ela foi e explicou o jeito que era para fazer. Falei que tinha dor nas costas e ela falou qual aparelho que era para fazer. Agora já sei. (E4; P.7; L.40-45).

Além dos monitores, é possível identificar que no espaço da ATI há placas com as instruções de exercícios de alongamento, que substituiu, há alguns meses, a placa com as instruções do uso dos aparelhos. Apesar de alguns expressarem a necessidade de haver um monitor em horários estabelecidos, isso não impede que todos façam o uso dos aparelhos, da mesma forma que outros alegam já terem experiência de como utilizálos. Uma entrevistada relata claramente essa questão: "Tinha a instrutora aqui para ajudar, dar aula. Agora não vem mais ninguém. Mas, como a gente também já sabe, não é?" (E1; P.2; L.52-53).

Devido a esse conhecimento relatado pela maior parte dos entrevistados, os mesmos sabem quais aparelhos utilizar ou não, da mesma forma que sabem quais são recomendados para partes específicas do corpo. Em cada aparelho há a indicação da musculatura envolvida quando o utiliza. Porém, os entrevistados que 
não receberam as instruções para a prática dos exercícios físicos relataram não se ater a essas informações, pois considera o uso dos aparelhos intuitivo, como no caso de um dos entrevistados, conforme o trecho exposto:

\begin{abstract}
Não tive instrução. Porque a gente olha nos aparelhos e muitos a gente já sabe. Esse aqui está sem a placa, mas tem aqueles [em outras ATIs] que tem a placa indicando, entendeu? Aqui não sei se tiraram, mas tem outras que você vai e em cada aparelho tem explicando toda a movimentação. Aqui a gente vai pelo manual mesmo. A gente chega e sabe. (E5; P.10; L.51-53).
\end{abstract}

Porém, por um lado, a falta de instruções e informações específicas sobre o uso de cada aparelho pode contribuir para que os usuários os utilizem de forma equivocada, podendo até causar lesões, indo contra o propósito da ATI. Por outro lado, não justificando a falta de informações disponíveis, da mesma forma que alguns usuários consideram o uso dos aparelhos como algo intuitivo, outros os utilizam à sua maneira, evitando ultrapassar os limites do corpo, assim como relatado: "Eu não esforço muito. Eu faço um pouquinho de cada um e depois vou embora. Se forçar muito, dependendo do aparelho complica. Começa a doer o braço, porque você se forçou" (E11; P.21; L.18-21). Observou-se ainda, durante uma das entrevistas, que uma usuária utilizava determinado aparelho para atingir o mesmo objetivo (fortalecimento de pernas e panturrilha), porém de forma diferente da recomendada, conforme placa de instrução padrão da Secretaria da Saúde, presente em outra ATI, próxima ao Bairro da Vila Santo Antônio, conforme informado pela usuária.

Esse contexto, apresentado pelos entrevistados, remete às criatividades das táticas do homem ordinário, denominado por Certeau (2014). Essas táticas emergem da capacidade desses usuários conseguirem perceber que o uso dos aparelhos pode avançar além daquilo que é instruído, especialmente nesse caso, posto que os mesmos frequentam a ATI há algum tempo, e com a ausência de instruções de profissionais da área, ficam à mercê dos ensinamentos de anos atrás. Da necessidade de inovar, muitos vão contra a corrente do que é divulgado pela Prefeitura, ou seja, de não buscar instruções com profissionais, e acabam criando sua própria maneira de exercitar-se.

Os idosos que frequentam a ATI na Vila Santo Antônio apropriaram-se do espaço de forma a definir sua maneira de utilizar os equipamentos dispostos no espaço público por meio de ações e estratégias da Prefeitura quanto à promoção da saúde e da qualidade de vida. A saúde e a qualidade de vida são questões que mais se destacam nos comentários dos entrevistados, porém conquistadas pelas diferentes maneiras de utilizar os aparelhos, conforme julgamento dos entrevistados, que muitas vezes ensinam a outros usuários.

\title{
6.5 A CONVIVÊNCIA NO ESPAÇO DA ATI
}

Partindo da compreensão de que grande parte dos idosos entrevistados moram sozinhos e são viúvos, com exceção daqueles que são casados e moram com seus cônjuges, conforme Quadro 1, se não houver a convivência entre vizinhos da rua ou até mesmo do bairro, muitos ficam dependentes do convívio familiar, o que pode não ocorrer diariamente. Por meio das entrevistas, foi possível identificar que, diante da instauração da ATI, o espaço vai além de uma simples composição de dez aparelhos para realizar atividades físicas, permitindo também uma convivência harmoniosa entre aqueles que frequentam a academia.

Essa convivência abrange as fronteiras dos cumprimentos educados entre os frequentadores da ATI. Por mais que não haja uma superlotação da academia, identificou-se que, entre aqueles que estão utilizando os aparelhos, há o respeito e o entendimento sobre 0 uso dos mesmos, não havendo disputas para usá-los. Convergente a isso, muitos ajudam um ao outro na utilização dos equipamentos da ATI, às vezes aconselhando e direcionando quais aparelhos utilizar ou não. Isso acontece por parte dos usuários mais assíduos com os frequentadores mais recentes que não receberam as instruções. Essas relações sociais estabelecidas entre os frequentadores contribuem para a construção de novas territorialidades, uma vez que essa se constitui, conforme Raffestin (1993, p. 160), uma espécie de "soma" das "relações mantidas por um sujeito com o seu meio".

Por ser uma academia que existe há quase dez anos e alguns frequentadores a utilizam desde a inauguração, criou-se um vínculo entre os mesmos, contribuindo até mesmo para o surgimento de um grupo de caminhadas matinais, do qual duas das entrevistadas fazem parte. Apesar de alguns usuários não terem costume de realizar as caminhadas no horário do grupo, realizam-na posteriormente, o que não deixa de 
caracterizá-los como os amigos da ATI, conforme uma entrevistada relatou: "A gente é bem amiga. [...]. Eu falo que é minha amiga da ATI. Quase todas conheci aqui" (E4; P.8; L.68-72).

Essas amizades nem sempre são de muito anos, como no caso de um dos entrevistados que é considerado o novo integrante da ATI há um mês. Percebe-se que aqueles que já frequentam há alguns anos a ATI são receptíveis a novos usuários, o que pode ser identificado por meio do relato do entrevistado que frequenta a ATI na Vila Santo Antônio há menos tempo: "Nesses 30 dias eu já arrumei 5 colegas já aqui. Amigão. [...]. Ficar preso dentro de casa é ruim. Porque você enjoa da TV. Aqui nós conversamos, não tem ninguém bravo" (E11; P.22; L.52-60).

Portanto, dentre toda a convivência, a prática dos exercícios físicos é acrescida de diversão e companheirismo, resultado de histórias e experiências compartilhadas diariamente. Por meio das táticas, que Certeau, Giard e Mayol (2013) denominam, os idosos que frequentam a ATI na Vila Santo Antônio criaram ali um espaço de convívio mútuo, marcado por suas práticas cotidianas. Essas práticas cotidianas contribuíram para criar características simbólicas no espaço da academia, representando sentimento de pertencimento ao espaço e ao grupo que ali frequenta, bem-estar e prazer por estar naquele espaço, contribuindo para a harmonia da vida cotidiana, tanto no espaço da ATI quanto no bairro. Observa-se, ainda, que os comportamentos dos entrevistados são percebidos por meio da valorização atribuída ao espaço da academia e o respeito entre os mesmos, resultando em benefícios simbólicos, o que Certeau, Giard e Mayol (2013) apontam como o contrato implícito da conveniência.

\section{6 (RE)INVENÇÃO COTIDIANA POR MEIO DO "FAZER ATI"}

Marcado pelos benefícios de saúde, qualidade de vida e sociabilidade, o "fazer ATI", assim como os entrevistados expressam com relação à prática de atividades físicas na Academia da Terceira Idade, modificou o cotidiano de seus usuários. Anteriormente à ATI, assim como já mencionado sobre o não uso do espaço urbano, os idosos entrevistados não tinham costume de exercitar-se semanalmente. $O$ que faziam eram caminhadas ao redor da praça ou exercícios de alongamentos no salão paroquial, sem grandes preocupações. Na maioria dos casos, essa circunstância estava aliada à falta de incentivo e de divulgação da necessidade dos exercícios físicos para a saúde, tanto física como mental.

Os entrevistados revelaram que o "fazer ATI" proporcionou algumas mudanças de hábitos, alterando desde pequenos eventos àqueles mais relevantes no cotidiano. Para começar, a atitude e o comportamento são dois aspectos que podem ser apontados como as mudanças ocorridas. Por meio das falas dos entrevistados, percebeu-se a preocupação com os aspectos que englobam a prática da atividade física, que foi intensificado a partir da instauração da ATI. Chamou a atenção a consciência que os usuários demonstraram quanto à importância da ATI e como ela tem papel fundamental em seu cotidiano. Essa valorização pode ser percebida na fala da entrevistada a seguir:

Se [eu] não vir, vou acabar ficando atada. Porque eu fico só lá sentada e deitada, deitada, deitada. Então, ela [a nora] vem me trazer para andar um pouquinho, segurando em mim, trazendo aqui para fazer a ginástica, fica me levando de um em um. [...]. Se eu fico assim, dois três dias sem vir, aí vou ficando ruim, daí eu venho e parece que já dá uma animadinha. (E8; P.14; L.54-56).

A disposição também foi mencionada diversas vezes entre os entrevistados, sendo compreendida tanto como o estado de espírito, relacionado ao humor e ao ânimo, como também à condição física, resistência e energia para realizar alguma atividade dentro de casa ou externamente, frequentando outros lugares. Vinculado a esses aspectos, destaca-se a independência desses idosos, posto que em condições físicas equilibradas conseguem realizar suas atividades sozinhos e sem a ajuda constante de outra pessoa. Esses aspectos são identificados na fala apresentada a seguir:

Olha, eu assim mudar... porque desde que meu marido faleceu, já faz mais de 15 anos, eu moro sozinha, eu é que faço tudo. Eu vou ao mercado, eu tenho meu convênio do estado é atendido mais lá em Sarandi [cidade vizinha], eu vou de ônibus. [...]. Só quando eu não estou bem que a filha leva de carro. [...]. Viajo. Agora mesmo eu vou viajar para São Paulo. Vou sozinha de ônibus. Vou para Minas. (E2; P.5; L.75-79).

Revista Alcance - Eletrônica - vol. 25 - n. 1 - Jan./Abr. 2018 
Com relação à saúde, os entrevistados relataram a diminuição de dores no corpo e mais facilidade para locomoção, não necessitando de instrumentos como bengala e muleta, conforme pontuado por um dos entrevistados quando ressalta: "Se eu não fazer [ATI] eu travo e aí eu não ando. Igual meu irmão anda de muleta e irmã de andador" (E7; P.13; L.20-21). Destaca-se, também, o desenvolvimento saudável quanto às doenças de hipertensão, possibilitando a redução no consumo diário de remédios, por meio da fala de uma entrevistada: "Eu tomava seis tipos de remédio de pressão. Agora hoje eu só tomo dois. Um cedo e um à tarde" (E3; P.6; L.29-30).

No mesmo sentido, verificou-se que algumas situações, que antes dificultavam o bem-estar dos entrevistados, foram resolvidas e contribuíram para a saúde desses usuários, como a insônia enfrentada por alguns entrevistados, o que causava consequências negativas no cotidiano dos mesmos, até mesmo implicando a baixa imunidade e a disposição. Isso é percebido quando o entrevistado relata:

Eu não estava dormindo. Deitava dez horas e acordava duas horas, difícil dormir, andava com os olhos doendo. Agora que eu estou começando a frequentar aqui, eu deito dez horas, mas quando eu vejo já são cinco horas, durmo direto (risos). Eu acho que pelo menos para minha pessoa, está ótimo (E11; P.21; L.34-37).

Ademais, a instauração da ATI no bairro facilitou o acesso dos moradores e possibilitou que alguns que já praticavam exercícios em academias particulares pudessem suprimir essa despesa, passando a frequentar a academia pública, conforme mencionado por uma entrevistada: "Ah, a gente vai nessas academias e são caras. E além disso, é uns minutinhos só, paga caro. E aqui eu faço de graça e não pago nada... eu gosto" (E4; P.7; L.33-34). Observou-se, também, que alguns usuários puderam deixar de se colocar diante de alguns sacrifícios, que muitas vezes eram prejudiciais à saúde, para praticar exercícios físicos em outras localidades e começar a frequentar a ATI do bairro, como no caso de uma das entrevistadas que descreveu o seguinte relato:

Frequentava a Unimed, mas é muito longe lá e eu não podia entrar na circular [ônibus] que fazia aquele barulho e eu chegava lá tonta. Não aguentava quase nem fazer. [...]. Então, falei para ela [nora], ela falou 'vamos aqui então'. Aqui não tem tudo o que tem lá. Lá tem muita coisa, mas é melhor vir aqui do que ir lá. (E8; P.15; L.92-95).

Diante de todos esses aspectos que contextualizam a (re)invenção cotidiana dos idosos que frequentam a ATI na Vila Santo Antônio, além das questões que envolvem a convivência, conforme exposto anteriormente, observa-se que esses idosos tiveram seus modos de vida modificados conforme o processo de territorialização do espaço, que emergiu a partir de uma estratégia de política pública da Prefeitura. Convergente a isso, o cotidiano foi (re)inventado por meio das táticas que esses usuários, aqui denominados como homens ordinários, apropriaram-se do espaço (CERTEAU, 2014). Apropriação ocorreu diariamente e de forma criativa, resultado das relações e do convívio de cada um dos usuários e dos grupos que frequentam a ATI no bairro. Complementarmente, essa ação de apropriação ocorre como desdobramento da territorialidade expressada por meio dos usuários da Academia (COIMBRA; SARAIVA, 2013).

\subsection{A EXPECTATIVA QUANTO AO ESPAÇO DA ATI}

A prática dos exercícios físicos e a apropriação do espaço da ATI fazem parte do cotidiano dos usuários da mesma, conforme já apresentado. Nesse cenário, todos aqueles que participaram das entrevistas expressaram suas expectativas com relação ao espaço da ATI. Somente pelo fato de haver uma pessoa diferente buscando entrevistá-los já foi uma oportunidade encontrada pelos mesmos para relatar pontos de melhorias, pontuar as necessidades e os desejos, muitas vezes realizados em comparação a outras ATIs da cidade.

Por meio das entrevistas, identificou-se que, por mais que as expectativas variem, as mesmas são convergentes entre as opiniões dos usuários entrevistados. A falta de sombra no espaço por não haver árvores ao redor foi destacada por uma das entrevistadas: "Aqui nunca teve sombra. Podia ter uma árvore aqui. Mas, não tem. Tem que vir cedo porque depois o sol vem, já desanima" (E1; P.1; L.19-20). Complementarmente, a instalação de novos aparelhos também foi relatada entre os entrevistados, uma vez que praticam os mesmos exercícios com os mesmos aparelhos há quase dez anos e acreditam ser necessária a atualização desses, ou um monitor para ensinar novas formas de utilizar os aparelhos. Isso fica evidente nas falas de alguns 
entrevistados: "Eles deviam colocar mais aparelhos aqui. Aparelho novo. Porque a gente só faz esses que estão aqui. Tinha que ter uma bicicleta" (E8; P.16; L.158-159); "Eu acho que devia colocar os aparelhos que tem hoje em outras academias, em outros lugares, porque aqui faltam alguns [...]. Você pode ver tem ATI que tem e aqui não tem" (E10; P.19; L.78-79). Outros, ainda, indicaram que uma parte de um dos aparelhos quebrou e foi substituída por outro que já havia na ATI, ou seja, dentre os dez aparelhos padrão que compõem a ATI, na ATI da Vila Santo Antônio existem nove, como relatado: "Tinha mais aparelho, eles arrancaram e não puseram de volta" (E2; P.4; L.30-31).

Por fim, o desejo comunal dos entrevistados é que, apesar de melhorias, o governo municipal não retire ou extinga as academias. Ficou evidente a valorização e a importância da ATI para a vida desses usuários, posto que essa é uma das únicas alternativas e incentivos de exercitarem-se. Conforme relato a seguir, verificase claramente essa questão:

Espero que eles [Prefeitura] deixem isso aqui, não tirar isso aqui. Eu acho isso aqui muito bom. $O$ que a prefeitura fez aqui, eu acho que é bom. Se ela chega a tirar e propor outra coisa, fica ruim para nós que moramos aqui. (E11; P.23; L.140-142).

Há também a preocupação com o patrimônio público e permite-se dizer, ainda, com o espaço territorializado pelos usuários: "Tomara que não acabe. Tem vez que eu vejo a molecada mexendo [...]. Molecada que mexe numa coisa, mexe em outra. Não pode deixar, não custa nada, porque estragar o que está feito?!" (E4; P.9; L.107-109). A apropriação do território é percebida nesse relato, cujo usuário demonstra a importância do cuidado com o patrimônio público, em especial aquele utilizado rotineiramente por ele. Contudo, compreende-se que a ATI tanto contribuiu para (re)inventar o cotidiano desses usuários, proporcionando qualidade de vida, como a academia já está incorporada ao cotidiano dos mesmos, que apresentam receio de perdê-la.

\section{CONSIDERAÇÕES FINAIS}

Nesse artigo, procurou-se compreender como ocorre a territorialização do cotidiano dos moradores de um determinado bairro a partir da produção do espaço urbano por meio de intervenções governamentais com a implantação das ATIs, o que foi feito utilizando elementos extraídos das entrevistas realizadas com idosos que moram e frequentam semanalmente a ATI na Vila Santo Antônio, bairro do município de Maringá, PR. A partir das análises das entrevistas e da compreensão das falas dos idosos que frequentam a ATI no bairro em questão, percebeu-se a apropriação do espaço por parte dos mesmos. O espaço da ATI é pautado por movimentos e por territorialidades cotidianas dos usuários, que o construíram diante os movimentos de apropriação e uso.

Assim sendo, conforme as categorias extraídas por meio da análise, é possível apontar alguns achados que ressaltam a territorialização no cotidiano dos moradores a partir da instauração da ATI. Com relação ao espaço produzido, verificou-se a produção histórica e temporal do espaço, que antes considerado sem uso e apenas como uma parte abandonada da praça do bairro, passou, em aproximadamente dez anos, a ter importância para os moradores, particularmente os idosos, que praticam os exercícios físicos na ATI. Atualmente há uma expectativa quanto ao espaço agora territorializado, que é afirmado pelo receio de um dia esse espaço vir a ser desterritorializado, destruindo seu propósito e significado, marcado pela promoção da saúde e da qualidade de vida, assim como a convivência e a (re)invenção do cotidiano desses idosos. Diante disso, foi possível perceber que as novas territorialidades construídas por meio da apropriação do território fizeram com que também emergisse uma nova forma de experimentar a urbe, principalmente por meio do estabelecimento de relações sociais que surgiram após a instauração da ATI. Nesse sentido, a territorialidade adquire um valor bem particular, pois reflete a multidimensionalidade do vivido territorial pelos membros de uma coletividade (RAFFESTIN, 1993).

Destaca-se também a intervenção governamental realizada sem impactos negativos para a população, de forma que os idosos usuários se apropriaram de discursos que propagam os benefícios da ATI. Isso está diretamente relacionado com o que foi percebido sobre a influência da visão do chão quanto às tomadas de decisão daqueles que compõem os grupos que detêm a visão do alto. Pode-se dizer que a apropriação e o uso da ATI, por parte dos idosos, contribuem para difusão dessa estratégia de política pública, ou seja, as trajetórias e as histórias invisíveis se fazem necessárias para o desenvolvimento e compreensão de tais estratégias. Nesse sentido, a compreensão das territorialidades deve ser considerada para a formulação de

Revista Alcance - Eletrônica - vol. 25 - n. 1 - Jan./Abr. 2018 
estratégias de desenvolvimento socioespacial nas cidades, uma vez que elas refletem distintos aspectos do que é vivido em um dado território pelos membros de uma coletividade (SOUZA, 2009; SARAIVA; CARRIERI; SOARES, 2014).

Por fim, buscando articular as compreensões sobre a produção do espaço urbano, territórios e territorialização, e cotidiano para a realização do artigo em questão, delimitaram-se alguns requisitos e não se exploraram outros, mas esses podem ser estudados futuramente, de forma a enriquecer a compreensão sobre as consequências e as interferências da intervenção espacial urbana por meio das ATIs. É possível abranger o perfil daqueles que utilizam a ATI, como pessoas abaixo dos 60 anos, que também foram encontradas praticando os exercícios. Um cenário que está contribuindo para muitas ATIs serem denominadas não somente para idosos, mas como Academia ao Ar Livre. Assim como identificar os diferentes usos em outras ATIs da cidade. Faz-se pertinente, ainda, comparar os dois discursos, do alto e do chão. Isso é justificado devido algumas informações discrepantes encontradas durante a análise e que pôde ser percebida no decorrer da leitura. Ademais, ainda voltado para o cotidiano, buscar compreender outras necessidades da população idosa, que muitas vezes podem estar implícitas perante o sucesso e a grande divulgação da ATI.

\section{REFERÊNCIAS}

ATLAS BRASIL - Atlas do Desenvolvimento Humano no Brasil. Maringá, PR, 2013. Disponível em: $<$ http://www.atlasbrasil.org.br/2013/pt/perfil_m/maringa_pr>. Acesso em 21 mar. 2017.

BARDIN, L. Análise de conteúdo. Lisboa: Edições 70, 1979.

BRASIL. Lei n. 10.741, de $1^{0}$ de outubro de 2003. Disponível em: <http://www.planalto.gov.br/CCivil_03/leis/2003/L10.741.htm>. Acesso em: 05 jan. 2017.

BRASIL. Política Nacional de Promoção da Saúde: PNPS. Ministério da Saúde, Secretaria de Vigilância em Saúde, Secretaria de Atenção à Saúde. Brasília: Ministério da Saúde, 2015.

CANDIOTTO, L. Z. P.; SANTOS, R. A. Experiências geográficas em torno de uma abordagem territorial. In: SAQUET M. A.; SPOSITO E. S. (Org.). Territórios e territorialidades: teorias, processos e conflitos. São Paulo: Expressão Popular, 2009. p. 315-340.

CARLOS, A. F. A. A natureza do espaço fragmentado. In: SANTOS, M.; SOUZA M. M. A.; SILVEIRA, M. L. (Org.). Território: globalização e fragmentação. São Paulo: Editora HUCITEC, 1996. p. 222-228.

CARLOS, A. F. A. Da "organização" à "produção" do espaço no movimento do pensamento geográfico. In: CARLOS A. F. A.; SOUZA, M. L.; SPOSITO, M. E. B. (Org.). A produção do espaço urbano: agentes e processos; escalas e desafios. São Paulo: Contexto, 2013. p. 53-73.

CERTEAU, M. de. A invenção do cotidiano: 1. Artes de fazer. Petrópolis: Vozes, 2014

CERTEAU, M. de; GIARD, L.; MAYOL, P. A invenção do cotidiano: 2. morar, cozinhar. Petrópolis: Vozes, 2013.

COELHO, K. S. A resistência à nova proposta de Plano Diretor apresentada pela Prefeitura Municipal de Florianópolis: uma análise das práticas alternativas de organizar. 2012. 358f. Tese (Doutorado) - Universidade Federal de Santa Catarina, Centro Socioeconômico. Programa da Pós-Graduação em Administração, 2012.

COIMBRA, K. E. R.; SARAIVA, L. A. S. Territorialidade em uma organização-cidade: 0 movimento quarteirão do soul. Gestão \& Regionalidade, v. 29, n. 86, p. 34-46, 2013.

CORRÊA, R. L. 0 espaço urbano. São Paulo: Ática, 2004.

CORRÊA, R. L. Sobre agentes sociais, escala e produção do espaço: um texto para discussão. In: CARLOS A. F. A.; SOUZA, M. L.; SPOSITO, M. E. B. (Org.). A produção do espaço urbano: agentes e processos; escalas e desafios São Paulo: Contexto, 2013. p. 41-51.

DENZIN, N. K.; LINCOLN, Y. S. 0 planejamento da pesquisa qualitativa: teorias e abordagens. Porto Alegre: Artmed, 2006.

FUINI, L. L. Território, territorialização e territorialidade: 0 uso da música para a compreensão de conceitos geográficos. Terr@Plural, v. 8, n. 1, p. 225-249, 2014. 
GIARD, L. História de uma pesquisa. In: CERTEAU M. de. A invenção do cotidiano: 1. artes de fazer. Petrópolis, Rio de Janeiro: Vozes, 2014. p. 9-31.

HAESBAERT, R. Des-caminhos e perspectivas do território. In: RIBAS, A. D.; E. S. SPOSITO E. S.; SAQUET, M. A. (Org.). Território e desenvolvimento: diferentes abordagens. Francisco Beltrão: Unioeste, 2004. p. 87119.

Desterritorialização: entre as redes e os aglomerados de exclusão. In: I. E. CASTRO, I. E.; P. C. C. GOMES P. C. C.; CORRÊA R. L. (Org.). Geografia: conceitos e temas. Rio de Janeiro: Bertrand Brasil, 2012, p. 165-205.

Concepções de território para entender a desterritorialização. In: SANTOS, M.; BECKER, B. K. (Orgs.). Território, territórios: ensaios sobre o ordenamento territorial. 3. ed. Rio de Janeiro: Lamparina, 2007a, p.43-71.

Território e multiterritorialidade: um debate. GEOgraphia, ano IX, n. 17, p. 19-46, $2007 \mathrm{~b}$.

HARVEY, D. Do gerenciamento ao empresariamento: a transformação da administração urbana no capitalismo tardio. Espaço \& Debates, 39, p. 48-64, 1996.

HARVEY, D. A produção capitalista do espaço. São Paulo: Annablume, 2005.

LEFEBVRE, H. La prodiction de l'espace. Paris: Éditions Anthropos, 2000.

LEVIGARD, Y. E.; BARBOSA, R. M. Incertezas e cotidiano: uma breve reflexão. Arquivos Brasileiros de Psicologia, v. 62, n. 1, p. 84-89, 2010.

MEDEIROS, R. M. V. Território, espaço de identidade. In: SAQUET, M. A.; SPOSITO, E. S. (Orgs.). Territórios e territorialidades: teorias, processos e conflitos. São Paulo: Expressão Popular, 2009. p. 217-227.

MYRRHA, L. J. D. População. In: Instituto Brasileiro de Geografia e Estatística (IBGE). Brasil em números. Centro de Documentação e Disseminação de Informações, v. 24, p. 65-89, 2016.

NARDI, A. C. F., SAPATA, M. P. M.; Lopes, M. T. S. R. Plano municipal de saúde de Maringá-PR: 2014/2017, 2013. Disponível em: <http://www2.maringa.pr.gov.br/sistema/arquivos/b65b3c5fcd38.pdf>. Acesso em: 5 jan. 2017.

PALÁCIOS, A. R. O. P.; NARDI, A. C. F. Academia da Terceira Idade: promoção da saúde e atividade física em Maringá. Prefeitura Municipal de Maringá. Maringá, 1-6, 2009. Disponível em: <http://www2.maringa.pr.gov.br/sistema/arquivos/bc22009ce8cd.pdf>. Acesso em: 5 jan. 2017.

RAFFESTIN, C. Por uma geografia do poder. São Paulo: Ática, 1993.

SANTOS, M. O retorno do território. In: SANTOS, M.; SOUZA, M. M. A.; M. L. SILVEIRA, M. L. (Org.). Território: globalização e fragmentação. São Paulo: Hucitec/Anpur, 1994. p. 15-20.

SANTOS, M.; SILVEIRA, M. L. O Brasil: território e sociedade no início do século XXI. Rio de Janeiro: Record, 2006.

SAQUET, M. A. As relações de poder e os significados do conceito de território. In: SAQUET, A. M. (Org.). Abordagens e concepções de território. São Paulo: Outras Expressões, 2013. p. 27-35.

SARAIVA, L. A. S.; CARRIERI, A. P. Organização-cidade: proposta de avanço conceitual a partir da análise de um caso. Revista de Administração Pública, v. 46, n. 2, p. 547-576, 2012.

SARAIVA, L. A. S.; CARRIERI, A. P.; SOARES, A. S. Territorialidade e identidade nas organizações: $O$ caso do mercado central de Belo Horizonte. Revista de Administração Mackenzie, v.15, n.2, p.97-126, 2014.

SECRETARIA MUNICIPAL DE ESPORTES E LAZER. ATI's Maringá, 2017. Disponível em: $<$ http://www2.maringa.pr.gov.br/esportes/?cod=ati>. Acesso em 21 março 2017.

SHIMADA, N. E. Trajetórias anônimas no cotidiano da cidade: a territorialização do bairro Santa Felicidade pelos seus moradores. 2015. 235f. Dissertação (Mestrado em Administração) - Universidade Estadual de Maringá, Paraná, 2015.

SOUZA, C. Políticas públicas: uma revisão da literatura. Sociologias, v. 8, n. 16, p. 20-45, 2006.

SOUZA, M. L. O território: sobre espaço e poder, autonomia e desenvolvimento. In: CASTRO, I. E.; GOMES, P. C. C.; CORREAA, R. L. (Org.). Geografia: conceitos e temas. Rio de Janeiro: Bertrand Brasil, 2000. p. 77-116.

Revista Alcance - Eletrônica - vol. 25 - n. 1 - Jan./Abr. 2018 
SOUZA, M. L. "Território" da divergência (e da confusão): em torno das imprecisas fronteiras de um conceito fundamental. In: SAQUET, M. A.; SPOSITO, E. S. (Orgs.). Territórios e territorialidades: teorias, processos e conflitos. São Paulo: Expressão Popular, 2009. p. 57-72.

SOUZA, M. L. A cidade, a palavra e o poder: práticas, imaginários e discursos heterônomos e autônomos na produção do espaço urbano. In: CARLOS, A. F. A.; M. F. SOUZA, M. F.; SPOSITO, M. E. B. (Org.). A produção do espaço urbano: agentes e processos; escalas e desafios. São Paulo: Contexto, 2013. p. 147-166.

SOUZA FILHO, A. Michel de Certeau: fundamentos de uma sociologia do cotidiano. Sociabilidades, v. 2, p. 129-134, 2002.

TEIXEIRA, J. C.; SARAIVA, L. A. S; CARRIERI, A. P. Os lugares das empregadas domésticas. Organizações \& Sociedade, v. 22, n. 72, 2015.

VALVERDE, R. R. H. F. Transformações no conceito de território: competição e mobilidade na cidade. GeouspEspaço e Tempo, São Paulo, n. 15, p. 119-126, 2004.

YILMAZ, G. G. Tactics in daily life practices and different forms of resistance: The Case of Turks in Germany. Procedia - Social and Behavioral Sciences, v. 82, p. 66-73, 2013. 